\title{
The Application of Quality Control Circles to Reduce the Cost of Non-priced Consumables in Department of Oncology
}

\author{
Xiaofang Zhang, Jinglan Luo, Rui Dai, Lu Wang, Jieli Wei, Yingying Liang, Qiugui Huang, Yuyao Liu* \\ Department of Oncology, The First Affiliated Hospital of Jinan University, Guangzhou 510630, Guangdong \\ Province, China
}

\begin{abstract}
[Abstract] Objective: To investigate the effectiveness of using quality control circle (QCC) techniques to reduce the cost of non-priced consumables in medical oncology. Methods: Analytic statistics were compiled on the performance appraisal form. Aiming at the key points of improvement with respect to the excess cost of non-valuable consumables, the reasons were analyzed, and corresponding measures were formulated to compare the cost before and after the improvement. Results: After the QCC activity, the cost of non-priced consumables decreased from RMB 6.57/bed day to RMB 3.96/bed day. Conclusion: QCC has effectively reduced the cost of non-priced consumables in the oncology department, and it is worthy of promotion.
\end{abstract}

Key words: Quality control circles; Reduction; non-priced consumables; Cost

Publication date: May, 2021; Publication online: 31 May, 2021

*Corresponding author: Xiaofang Zhang, 455316446@qq.com

In October 2018, the General Office of the People's Government of Guangdong Provincial Government issued the Notice of the General Office of the Guangdong Provincial Government on Printing and Distributing the Implementation Plan for the Establishment of a Modern Hospital Management System in Guangdong Province (Yuefu Office [2018] No. 1), which puts forward clear requirements regarding strengthening public hospitals' cost management and accounting. The cost of consumables is an important part of hospital cost management. There are many types of medical consumables, and the coverage is wide. Among them, non-priced consumables or non-separately charged consumables refer to materials that are frequently used by medical institutions in the course of conducting medical services. These materials are not allowed to be charged to patients separately, in accordance with the regulations. In this context, consumption is high and prices vary widely. These costs are entirely borne by the hospital. Given that the unit price of most consumables is low, these costs are often easily neglected in cost management. ${ }^{[1]}$ It is particularly important to comply with the hospital's performance reform, strengthen departmental performance appraisal work, promote a more scientific and fair income distribution, realize efficiency and quality improvements, and reduce the cost of non-price consumables.

A quality control circle (QCC) is an automatically and spontaneously formed team comprised of (5-12) people in the same workplace to solve workplace problems and improve work performance. Team members divide the work and cooperate to apply quality control (QC) practices and tools and conduct various analyses to solve workplace problems and improve performance ${ }^{[2]}$.

Our oncology department conducted QCC activities from June to December 2019, focused on reducing the cost of non-priced consumables. We achieved significant results, which are reported below.

\section{Information and methodology}

\subsection{General information}

Based on the performance table, the expenditure on 
non-priced consumables from January to March 2019 was calculated using the following formula: consumption quota per unit bed day $=$ departmental consumption in the previous 3 months $\div$ actual number of bed days occupied in the department in the previous 3 months ${ }^{[3]}$. The cost overrun of non-priced consumables in June was then analyzed.

\subsection{Methods}

\subsubsection{Establishment of the QCC activity team}

The head nurse of the Department of Internal Medicine was appointed as the counselor, and the team members were seven nurses from the Department of Oncology. The department's head nurse was elected as the leader of the circle. The members each had individual duties toward completing the circle's work, including overall management, data collection, data analysis, the implementation of countermeasures etc.

\subsubsection{Classified statistic}

According to the classification principles of the Regulations on Supervision and Administration of Medical Devices and the Rules on Classification of Medical Device, coupled with the department's actual work, non-priced consumables were divided into six categories for statistical purposes, of which the disinfection and cleaning category included disinfectants, sterilizing pieces, etc.; the medical polymer material category included rubber surgical gloves, examination gloves, etc.; the nursing material category included medical dressings, sterilized cotton balls, sterilized cotton swabs, various bandages, medical tape, disposable masks, caps, disposable sterile towels, etc.; the living supplies category included a variety of adhesive bags, hand sanitizer, hand wipes, etc.; the office supplies category included A4 paper, various pens, toner cartridges, ink cartridges, etc.; and the instruments category included small surgical kits, straight forceps, curved forceps, etc ${ }^{[4]}$. Through classification and the use of the stratification method, this activity's improvements focus concentrated on the office supplies and living supplies categories of non-priced consumables, according to the $80 / 20$ principle.

\subsubsection{Intra-group discussion}

Intra-group discussion was held to analyze the causes of overspending on non-priced consumables. The circle members used the brainstorming method and the Ishikawa diagram to analyze the causes from four aspects, namely Man, Material, Method, and medium, and finally determined the actual causes by scoring the main causes, as follows: there was no item management system in the department; there was no designated person to manage the items; the items were not placed properly and were misappropriated and taken at will; there were duplicate claims; etc.

\subsubsection{The corresponding improvement measures were formulated using the unit bed-day consumption quota for non-priced consumables in the department as a target for improvement.}

\subsubsection{Developing an item management system}

The relevant literature on the management of non-priced consumables was consulted, ${ }^{[5-10]}$ and a system for managing non-priced consumables was discussed and developed to address the collection and storage of as well as access to and the corresponding management of non-priced consumables. The whole department was gathered to study the new system, clarify responsibilities, and implement management practices according to the system. The head nurse supervised the implementation of the measures and conducted weekly QC checks.

\subsubsection{Selecting a dedicated manager}

A dedicated manager of non-priced consumables was appointed; responsibilities included the development of a materials collection plan and inventory. A register was kept of items collected and picked up to facilitate usage statistics. Biweekly counting of non-priced consumables was conducted, and balances were counted prior to collection to determine whether there was a build-up of items.

\subsubsection{Fixed-point storage}

The storage room lock was upgraded to a combination lock to strengthen management. SPD(Supply Processing and Distribution) was enabled to perform the refined information management of non-priced consumables, with dynamic supervision of inventory and distribution throughout the whole process, and the sweeping of the code for access and to assign responsibility to the relevant person. Supplies were stored at fixed points after they were placed in the warehouse. Storage shelves for non-priced supplies were erected and labelled, and the items were arranged in an orderly manner to facilitate access and inventory, so as to avoid stock accumulation.

\section{Results}

Table 1 shows a comparison of the cost situation of non-priced consumables before and after the improvements, with a target compliance rate of $111.54 \%$ and an improvement rate of $39.73 \%$. 
Table 1. Comparison of the cost of non-priced consumables before and after improvements

\begin{tabular}{cccc}
\hline Time period & $\begin{array}{c}\text { Total monthly expenditure on } \\
\text { non-priced consumables (\$) }\end{array}$ & $\begin{array}{c}\text { Total number of bed days per } \\
\text { month (days) }\end{array}$ & $\begin{array}{c}\text { Cost of non-priced } \\
\text { consumables (\$/bed day) }\end{array}$ \\
\hline Before improvement & $20,398.11$ & 3,105 & 6.57 \\
After improvement & $14,527.19$ & 3,793 & 3.83 \\
Maintenance phase & $13,249.04$ & 3,304 & 4.01 \\
\hline
\end{tabular}

\section{Discussion}

With the rapid development of medical and health care, and the full implementation of the new medical reform policy, full coverage medical insurance, and changes in the way medical costs are paid, medical cost control has become a top hospital management priority, and among the three major parts of hospital expenditure, there is still large potential in the area of controlling excessive expenditure on consumables. Therefore, only by strengthening the management and control of medical consumables, eliminating waste and loss, and striving to reduce medical costs can patients' interests be effectively ensured and the burden on hospitals and patients reduced ${ }^{[3]}$.

The literature shows that the two most effective cost reducing components of cost management are procurement and consumption, of which low-value consumables should be managed with a focus on consumption management. ${ }^{[11]}$ Non-priced consumables have a low unit price and account for a small proportion of the cost, so they are often neglected and insufficiently managed; there are many categories of non-priced consumables, and the actual managers are often nursing staff, who lack professional management knowledge. Further, waste and misappropriation are high, which makes management difficult. In this project, the cost management of non-priced consumables was carried out departmentally, aiming to draw attention to and explore effective management methods to provide a reference for the management of non-priced consumables throughout the hospital as a whole.

The QCC management model was first introduced in Japan in 1962 by Dr. Kaoru Ishikawa. Its core idea is that it is suitable to implement QCC activities wherever there are people. The basic steps are based on the plan-do-check-action (PDCA) cycle, carried out through ten basic steps. China has been carrying out QC activities for more than 40 years. Application has been extended from the original scope of enterprise quality management to various industries including the medical and health care field. The goal of QCC management in the medical field is to enhance medical staff's awareness to identify and solve medical problems, improve staff morale and the medical work environment, and ultimately improve the quality of medical care, while reducing medical management costs and improving the efficiency of medical services. ${ }^{[12]}$ It has been reported that QCC activities are currently applied to the management of disposable medical consumables and non-priced consumables in the operating room with good results. ${ }^{[13-15]}$ Moreover, the intensive care unit used the QCC technique in consumables cost control, reducing costs significantly, by $65.5 \%$, after the improvement. ${ }^{[16]}$. Therefore, our department conducted QCC activities related to the cost of non-priced consumables, and at the end of the activities, the expenditure was reduced from $\$ 6.57 /$ bed day to $\$ 3.83 /$ bed day, with a target compliance rate of $111.54 \%$ and an improvement rate of $39.73 \%$. The effect has been maintained. To date, the expenditure of non-priced consumables has been slightly lower than the consumption quota per unit bed day. Hence, the countermeasures are effective and can comprise a standardized process for continuous implementation.

Through this activity, nurses can proactively identify and solve problems, and flexibly use a variety of charting methods to summarize, thus making problems and countermeasures more intuitive, improving scientific thinking, organizational, and coordination skills, and contributing to rapid problem solving. This activity is worthy of promotion as it has established an awareness of saving among medical and nursing staff, standardized the use of various consumables, strengthened cost control and optimized the workflow, and effectively contributed to the 
reduction of medical costs for patients.

\section{References}

[1] Gao JJ, Chen FQ, Zhou W, et al. A preliminary study on the price management of disposable medical consumables that cannot be charged separately [J]. China Hospitals, 2017, 21(11):75-77.

[2] Zhang XG, et al. Hospital quality control circle coaching manual $[\mathrm{M}]$. People's Health Publishing House, 2012:3-4.

[3] Wang F, Tan TL, Wang AP, et al. Management of medical low-value non-priced consumables [J]. Journal of Traditional Chinese Medicine Management, 2015, 23(08):167-168.

[4] Sun R. Standardized classification and management of medical consumables in hospital use [J]. China Medical Device Information, 2018, 24(09):155-157.

[5] Tan AZ, Wu MD, Xie JL, et al. Current situation and improvement strategies for the management of non-priced medical consumables [J]. Chinese Health Economics, 2014(4):85-86.

[6] Li HC, Yun FY, Liu XH, et al. Discussion on the management of low-value medical supplies in hospitals [J]. China Medical Equipment, 2019.16(7):152-155.

[7] Luo TT, Xu J, Chu XQ, et al. Exploration of cost control methods for non-priced surgical medical consumables [J]. Health Economics Research, 2017(08):48-50.

[8] Ren L, Wu XD, Huang J, et al. Using information data to achieve cost control of hospital materials: the Twenty-Sixth Annual Academic and Technical
Exchange Conference of China Association of Medical Equipment, Suzhou, Jiangsu, China, 2017 [C].

[9] Zheng QY, Wang XL. A practical study of 5S management method in medical disposables management $[\mathrm{J}]$. China Health Industry, 2019,16(07):66-67.

[10] Wu WC, Qin LR, Xu HQ. The impact of using SPD management model on the fine management of medical consumables in hospitals [J]. China Medical Devices, 2018, 33(9):153-157.

[11] He Q, Cheng SS, Wu R. Cost control of hospital materials [J]. China Medical Device Information, 2010, 16(11):5-7.

[12] Wang LR, Wang Y, Lou Y, et al. The role of quality control circles in sustained improvement of medical quality [J]. Springerplus, 2013,2(1):141.

[13] Hong SJ, Hu WL. The application of quality control circle activities in the management of intraoperative disposable medical supplies [J]. Journal of Nurses Training, 2011, 26(17):1560-1561.

[14] Xu WW. Application of quality control circle in the management of disposable medical supplies in the operating room [J]. Journal of Traditional Chinese Medicine Management, 2017, 25(04):127-128.

[15] Xie LP. Application of quality control circle in reducing the waste rate of non-priced consumables in the operating room $[\mathrm{J}]$. Medical Information, 2015, 28(47):309.

[16] Yang SJ, Sun JN, Wang YY. Application of quality control circle on cost control of consumables in ICU [J]. The Journal of Medical Theory and Practice, 2014,27(13):1818-1819. 